\title{
Intra-specific genetic diversity in wild olives (Olea europaea ssp cuspidata) in Hormozgan Province, Iran
}

\author{
Z. Noormohammadi ${ }^{1}$, H. Samadi-Molayousefi ${ }^{1}$ and M. Sheidai ${ }^{2}$ \\ ${ }^{1}$ Department of Biology, School of Basic Sciences, \\ Science and Research Branch, Islamic Azad University, Tehran, Iran \\ ${ }^{2}$ Shahid Beheshti University, GC, Faculty of Biological Sciences, Tehran, Iran \\ Corresponding author: Z. Noormohammadi \\ E-mail: z-nouri@srbiau.ac.ir
}

Genet. Mol. Res. 11 (1): 707-716 (2012)

Received August 19, 2011

Accepted January 10, 2012

Published March 19, 2012

DOI http://dx.doi.org/10.4238/2012.March.19.4

\begin{abstract}
Wild olive (O. europaea ssp cuspidata) plants grow in various regions of Iran and are expected to have considerable genetic diversity due to adaptation to the various environmental conditions. We examined the genetic diversity of four populations of wild olive growing in Hormozgan Province located in southern Iran by using 30 RAPDs and 10 ISSR markers. The mean value of polymorphism for RAPD loci was $73.71 \%$, while the value for ISSR loci was $81.74 \%$. The Keshar population had the highest value of intra-population polymorphism for both RAPD and ISSR loci (66.86 and 62.71\%, respectively), while the Tudar population had the lowest values $(20.35$ and $28.81 \%$, respectively). Similarly, the highest and lowest number of effective alleles, Shannon index and Nei's genetic diversity were also found for these two populations. The highest value of $\mathrm{H}_{\mathrm{pop}} / \mathrm{H}_{\mathrm{sp}}$ within population genetic diversity for RAPD and ISSR loci was found for the Keshar population $\left(\mathrm{H}_{\mathrm{pop}}=0.85\right.$ and $\left.\mathrm{H}_{\mathrm{sp}}=0.90\right)$. OPA04-750, OPA13650 and OPA02-350 RAPD bands were specific for Tudar, Bondon and Keshar populations, respectively, while no specific ISSR bands
\end{abstract}


were observed. Analysis of molecular variance as well as the pairwise $F_{\text {ST }}$ test showed significant differences for RAPD and ISSR markers among the populations. The NJ and UPGMA trees also separated the wild olive populations from each other, indicating their genetic distinctness. UPGMA clustering of the four wild olive populations placed the Tudar population far from the other populations; Keshar and Bokhoon population samples revealed more similarity and were grouped together. We conclude that there is high genetic diversity among $O$. europaea ssp cuspidata populations located in southern Iran. We also found RAPD and ISSR markers to be useful molecular tools to discriminate and evaluate genetic variations in wild olive trees.

Key words: AMOVA; Genetic diversity; ISSRs; RAPDs; Wild olive

\section{INTRODUCTION}

Wild olives are distributed from South Africa to South Asia, in the Sahara mountains, Macaronesia and Mediterranean countries (Green, 2002). Olea europaea ssp europaea and $O$. europaea ssp cuspidata are two subspecies with large geographical distribution: ssp europaea occurs in the Mediterranean basin and ssp cuspidata is distributed from Africa to China. These taxa are allogamous and their seeds are dispersed by birds (Spennemann and Allen, 2000; Green, 2002). Hybridization and gene flow between different taxa in olive complex have been reported by various authors (Belaj et al., 2007; Besnard et al., 2001, 2008). This phenomenon could help recover genetic erosion among olive cultivars (ssp europaea L.).

Recently, Azadi (2005) considered O. europaea ssp cuspidata as the only wild olive species in Iran, which is mostly grown in southern and western parts of the country, along with cultivated olives (ssp europaea), suggesting possible hybridization between wild and cultivated olive trees; hybridization has been reported by Sheidai et al. (2010) in southern Iran. Based on morphological and molecular data, Sheidai et al. (2010) also reported on intraspecific forms within the ssp cuspidata.

In recent years, molecular markers have played a major role in the evaluation of genetic diversity and genetic differentiation among populations. RAPD and SSR markers are useful tools to discriminate olive cultivars (Noormohammadi et al., 2007; Omrani-Sabbaghi et al., 2007) and to evaluate genetic diversity in wild olive populations (Sheidai et al., 2010). We examined genetic diversity and relationships in four wild olive populations growing in Hormozgan Province (southern Iran) by using RAPD and ISSR.

\section{MATERIAL AND METHODS}

Fresh leaves of four wild olive (O. europaea ssp cuspidata) populations including Bokhoon, Keshar, Tudar, and Bondon in Hormozgan Province were collected in spring 2011 (Table 1). At each site, three to 12 different individuals (trees) were selected and their leaves cleaned and placed in plastic bags, with and without silica gel beads, and then transported to the laboratory.

Three to five leaves of each sample were used for DNA extraction. The total genomic DNA was extracted following the CTAB method using DNeasy Plant mini kit (Qiagen 
GmbH., Germany), according to manufacturer instructions. The quality of DNA was examined by running on a $0.8 \%$ agarose gel.

Table 1. Sample details of the wild olive populations from Iran.

\begin{tabular}{llc}
\hline Population & Geographical locality in Hormozgan Province & Population size \\
\hline Keshar & $19^{\circ} 180^{\prime}$ to $19^{\circ} 276^{\prime} \mathrm{N}, 55^{\circ} 028^{\prime}$ to $54^{\circ} 905^{\prime} \mathrm{E}$ & 12 \\
Bokhoon & $57^{\circ} 270^{\prime}$ to $57^{\circ} 336^{\prime} \mathrm{N}, 15^{\circ} 040^{\prime}$ to $14^{\circ} 974^{\prime} \mathrm{E}$ & 10 \\
Bondon & $59^{\circ} 490^{\prime}$ to $59^{\circ} 759^{\prime} \mathrm{N}, 12^{\circ} 636^{\prime}$ to $12^{\circ} 925^{\prime} \mathrm{E}$ & 5 \\
Tudar & $58^{\circ} 065^{\prime} \mathrm{N}, 15^{\circ} 357^{\prime} \mathrm{E}$ & 3 \\
\hline
\end{tabular}

\section{RAPD and ISSR amplification}

Thirty RAPD primers of different Operon kits (A, C, I, M, H) from Operon Technologies, USA, as well as six combined primers were used (Table 2). RAPD reactions were conducted in a $20-\mu \mathrm{L}$ reaction mixture containing $50 \mathrm{ng}$ template DNA solution; 1X PCR buffer (10 mM Tris-HCl buffer, $\mathrm{pH} 8,50 \mathrm{mM} \mathrm{KCl}$ ); $1.5 \mathrm{mM} \mathrm{Mg}^{2+} ; 200 \mu \mathrm{M}$ dNTP mix and $1.0 \mathrm{U}$ Taq polymerase (Bioron, Germany). The PCR thermal program included an initial denaturation for $5 \mathrm{~min}$ at $95^{\circ} \mathrm{C}$, followed by 35 cycles of $1 \mathrm{~min}$ at $95^{\circ} \mathrm{C}, 1 \mathrm{~min}$ at $37^{\circ} \mathrm{C}, 2 \mathrm{~min}$ at $72^{\circ} \mathrm{C}$, and a final extension for $10 \mathrm{~min}$ at $72^{\circ} \mathrm{C}$.

The 10 ISSR primers used in the present study were UBC807, UBC810, UBC811, UBC823, UBC834, and UBC849 commercialized by UBC (the University of British Columbia) as well as (CA)9GT, (GA)9T, (GA)9A, and (GA)9C (Table 2). PCRs were performed in a $25-\mu \mathrm{L}$ volume containing $10 \mathrm{mM}$ Tris- $\mathrm{HCl}$ buffer, $\mathrm{pH} 8,50 \mathrm{mM} \mathrm{KCl} ; 1.5 \mathrm{mM} \mathrm{MgCl}$; $0.2 \mathrm{mM}$ of each dNTP; $0.2 \mu \mathrm{M}$ of a single primer; $20 \mathrm{ng}$ genomic DNA and 1.0 U Taq DNA polymerase (Bioron). Amplification reactions were performed in a Techne thermocycler (Germany) with the following program: a 5-min initial denaturation step at $94^{\circ} \mathrm{C}, 30 \mathrm{~s}$ at $94^{\circ} \mathrm{C} ; 45$ s at $50^{\circ} \mathrm{C}, 2 \mathrm{~min}$ at $72^{\circ} \mathrm{C}$, and a final extension step of $10 \mathrm{~min}$ at $72^{\circ} \mathrm{C}$.

Amplification products were visualized by running on a $2 \%$ agarose gel in $0.5 \mathrm{X}$ TBE buffer system, followed by ethidium bromide $(0.5 \mu \mathrm{g} / \mathrm{mL})$ staining. Fragment size was estimated by using a 100-bp molecular size ladder (Fermentas, Germany). Reproducible bands of each locus were scored as binary present (1) or absent (0) and data matrices of RAPD and ISSR loci were assembled for further analysis.

The effective number of alleles, percentage of polymorphic loci and Shannon's index were determined for both RAPD and ISSR loci by POPGENE version 1.31 (Yeh et al., 1999) for all loci and also for each population separately. Inter-population genetic diversity was determined by Nei's gene diversity $(\mathrm{H})$. $\mathrm{H}$ was calculated at the population $\left(\mathrm{H}_{\mathrm{pop}}\right)$ and species levels $\left(\mathrm{H}_{\mathrm{sp}}\right)(\mathrm{Nei}, 1973)$. Analysis of molecular variance was performed to reveal significant genetic differences between populations using GenAlex 6.4 (Peakall and Smouse, 2006).

UPGMA (unweighted paired group using arithmetic average) and neighbor joining (NJ) clustering were performed to study the population relationships.

Various similarity matrices [for example, Jaccard, Nei and Li (Podani, 2000)] were used for clustering. Ordination plot based on principal coordinate (PCO) analysis was also used for grouping of the trees by NTSYS-pc version 2.02 (Rohlf, 1998). Cophenetic correlation and bootstrapping was performed to check the fit of the dendrograms obtained (Podani, 2000), and the Mantel test (Mantel, 1967) was performed for estimating the correlation between RAPD and ISSR trees. 


\section{RESULTS}

\section{RAPD and ISSR amplification}

Eighteen of 30 RAPD primers used could produce reproducible bands, ranging in size from 280 to $3000 \mathrm{bp}$. In total, 140 polymorphic bands/loci and 32 common bands were obtained, with an average of 9.5 bands for each primer. The combined RAPD primers did not produce scorable bands except the OPC11/OPI18 locus (Table 2).

Table 2. RAPD and ISSR loci used in the study of wild olives and the genetic parameters.

\begin{tabular}{|c|c|c|c|c|c|c|c|}
\hline & Size range (bp) & $N_{\mathrm{A}}$ & $\mathrm{P} \%$ & $I$ & $N_{\mathrm{E}}$ & $H$ & Unique alleles \\
\hline \multicolumn{8}{|l|}{ RAPD primer } \\
\hline OPA02 & $300-1500$ & 13 & 92.31 & $0.429(0.212)$ & $1.447(0.312)$ & $0.278(0.157)$ & 1 \\
\hline OPA03 & $400-1150$ & 9 & 77.78 & $0.415(0.289)$ & $1.499(0.416)$ & $0.281(0.211)$ & 0 \\
\hline OPA04 & $400-1200$ & 10 & 90 & $0.419(0.265)$ & $1.488(0.410)$ & $0.278(0.201)$ & 1 \\
\hline OPA05 & $450-1200$ & 6 & 16.67 & $0.073(0.163)$ & $1.053(0.419)$ & $0.035(0.085)$ & 0 \\
\hline OPA09 & $300-1600$ & 11 & 63.63 & $0.348(0.311)$ & $1.428(0.443)$ & $0.237(0.224)$ & 0 \\
\hline OPA10 & $350-2000$ & 11 & 100 & $0.596(0.116)$ & $1.734(0.248)$ & $0.410(0.100)$ & 0 \\
\hline OPA11 & $800-1300$ & 9 & 100 & $0.458(0.185)$ & $1.472(0.287)$ & $0.295(0.145)$ & 0 \\
\hline OPA13 & $450-1800$ & 9 & 88.89 & $0.421(0.279)$ & $1.500(0.410)$ & $0.283(0.208)$ & 1 \\
\hline OPA18 & $400-2000$ & 8 & 25 & $0.149(0.278)$ & $1.177(0.343)$ & $0.102(0.192)$ & 0 \\
\hline OPC06 & $280-2600$ & 11 & 100 & $0.568(0.101)$ & $1.654(0.230)$ & $0.384(0.090)$ & 0 \\
\hline OPC08 & $380-1250$ & 9 & 88.89 & $0.404(0.208)$ & $1.399(0.302)$ & $0.257(0.151)$ & 0 \\
\hline OPC11/OPI18 & $300-1900$ & 6 & 66.67 & $0.332(0.270)$ & $1.330(0.304)$ & $0.214(0.180)$ & 0 \\
\hline OPI12 & $300-1500$ & 8 & 62.50 & $0.270(0.273)$ & $1.279(0.333)$ & $0.173(0.189)$ & 0 \\
\hline OPI16 & $300-3000$ & 12 & 100 & $0.389(0.144)$ & $1.340(0.233)$ & $0.235(0.115)$ & 0 \\
\hline OPI18 & $300-2000$ & 7 & 100 & $0.426(0.219)$ & $1.454(0.368)$ & $0.274(0.175)$ & 0 \\
\hline OPR08 & $350-1500$ & 9 & 100 & $0.407(0.208)$ & $1.419(0.361)$ & $0.257(0.168)$ & 0 \\
\hline OPH19 & $300-2000$ & 11 & 54.55 & $0.341(0.329)$ & $1.428(0.428)$ & $0.237(0.157)$ & 0 \\
\hline OPM19 & $300-3000$ & 13 & 100 & $0.568(0.156)$ & $1.697(0.307)$ & $0.388(0.132)$ & 0 \\
\hline Mean & - & 9.55 & 73.71 & 0.389 & 1.351 & 0.256 & 0.22 \\
\hline \multicolumn{8}{|l|}{ ISSR primers } \\
\hline UBC810(GA)8T & $350-2000$ & 7 & 71.42 & $0.388(0.291)$ & $1.444(0.395)$ & $0.260(0.206)$ & 0 \\
\hline UBC807(AG)8T & $400-2000$ & 9 & 88.89 & $0.477(0.254)$ & $1.580(0.400)$ & $0.324(0.193)$ & 0 \\
\hline UBC $849(\mathrm{GT}) 8 \mathrm{YA}$ & $400-1400$ & 4 & 100 & $0.608(0.097)$ & $1.752(0.236)$ & $0.420(0.088)$ & 0 \\
\hline UBC834(AG)8YT & $400-1800$ & 6 & 33.33 & $0.147(0.232)$ & $1.127(0.206)$ & $0.091(0.144)$ & 0 \\
\hline UBC811(GA)8C & $350-1700$ & 6 & 100 & $0.582(0.027)$ & $1.651(0.067)$ & $0.393(0.025)$ & 0 \\
\hline UBC823(TC)8C & $650-2000$ & 4 & 75 & $0.370(0.282)$ & $1.383(0.343)$ & $0.240(0.196)$ & 0 \\
\hline (CA)9GT & $300-1300$ & 3 & 100 & $0.542(0.096)$ & $1.582(0.237)$ & $0.359(0.088)$ & 0 \\
\hline (GA)9T & $200-2000$ & 10 & 90 & $0.484(0.239)$ & $1.575(0.372)$ & $0.327(0.181)$ & 0 \\
\hline (GA)9A & $370-1000$ & 4 & 75 & $0.170(0.340)$ & $1.237(0.475)$ & $0.121(0.243)$ & 0 \\
\hline (GA)9C & $150-350$ & 6 & 83.83 & $0.453(0.258)$ & $1.833(0.408)$ & $0.304(0.189)$ & 0 \\
\hline Mean & - & 5.9 & 81.74 & 0.422 & 1.516 & 0.283 & 0 \\
\hline
\end{tabular}

The mean value of polymorphism for RAPD loci was $73.71 \%$, with the highest values for the primers OPA10, OPA11, OPC06, OPI16, OPI18, OPR08, and OPM19 (100\%) and the lowest value for the OPA05 primer (16.67\%). The highest number of effective alleles was obtained for the OPA10 primer (1.73) while the lowest value was obtained with the OPA05 primer (1.05). OPA2, OPA4 and OPA13 RAPD primers produced three unique alleles (OPA02-350, OPA04-750 and OPA13-650).

The mean value of the Shannon index as a measure of genetic diversity was 0.38 for all primers, with the highest value for the OPA10 primer (0.59) and the lowest value for the OPA05 primer $(0.07)$. The highest value of Nei's genetic diversity $(\mathrm{H})$ for RAPD loci was found for the OPA10 (0.41) primer and the lowest value was observed with the OPA05 primer (0.03). 
Ten ISSR primers produced 59 reproducible bands ranging between 150 and $2000 \mathrm{bp}$. The highest value of ISSR band polymorphism was obtained with (CA)9GT (100\%), while the lowest value was obtained with the primer UBC834 (33\%). The mean value of ISSR band polymorphism across all loci was $81.74 \%$.

The UBC849 primer gave the highest number of effective alleles (1.75), Shannon index $(0.60)$ and Nei's genetic diversity $(0.42)$ among the ISSR primers, while the UBC834 primer gave the lowest values for these parameters.

\section{Intra- and inter-population diversity}

Among the four wild olive populations, the Keshar population showed the highest value of intra-population RAPD band (loci) polymorphism, while the Tudar population gave the lowest value (Table 3). Similarly, the highest and lowest numbers of effective alleles, Shannon index and Nei's genetic diversity were also obtained for these two populations.

Table 3. Genetic parameters among wild olive populations based on RAPD and ISSR loci.

\begin{tabular}{llcccccc}
\hline & Population & $\mathrm{P} \%$ & $I$ & $N_{\mathrm{E}}$ & $\mathrm{H}_{\mathrm{pop}}$ & $\mathrm{H}_{\mathrm{pop}} / \mathrm{H}_{\mathrm{sp}}$ & $\left(\mathrm{H}_{\mathrm{sp}}-\mathrm{H}_{\mathrm{pop}} / \mathrm{H}_{\mathrm{sp}}\right.$ \\
\hline RAPD & Keshar & 66.86 & $0.342(0.276)$ & $1.386(0.369)$ & $0.227(0.195)$ & 0.850 & 0.150 \\
& Bokhoon & 62.79 & $0.334(0.287)$ & $1.388(0.383)$ & $0.224(0.202)$ & 0.838 & 0.161 \\
& Bondon & 44.75 & $0.251(0.294)$ & $1.299(0.386)$ & $0.170(0.205)$ & 0.635 & 0.364 \\
& Tudar & 20.35 & $0.111(0.224)$ & $1.122(0.265)$ & $0.073(0.151)$ & 0.275 & 0.724 \\
\multirow{2}{*}{ ISSR } & & & & & \\
& Keshar & 62.71 & $0.377(0.310)$ & $1.480(0.428)$ & $0.261(0.221)$ & 0.909 & 0.090 \\
& Bokhoon & 42.37 & $0.233(0.292)$ & $1.278(0.380)$ & $0.158(0.204)$ & 0.550 & 0.452 \\
& Bondon & 52.54 & $0.322(0.319)$ & $1.414(0.437)$ & $0.224(0.227)$ & 0.780 & 0.219 \\
& Tudar & 28.81 & $0.188(0.300)$ & $1.253(0.409)$ & $0.133(0.213)$ & 0.463 & 0.536 \\
\hline
\end{tabular}

$\mathrm{P} \%=$ polymorphism \%; $I=$ Shannon index; $N_{\mathrm{E}}=$ number of effective alleles; $\mathrm{H}_{\mathrm{pop}}$ and $\mathrm{H}_{\mathrm{sp}}=$ Nei's genetic diversity for population and species levels, respectively; numbers in parentheses $=$ standard deviation. $^{\mathrm{sp}}$.

The highest value of $\mathrm{H}_{\mathrm{pop}} / \mathrm{H}_{\mathrm{sp}}$ as the indication of genetic diversity (for RAPD markers) within populations was found for the Keshar population, while the Tudar population had the highest value of genetic diversity among populations (Table 3 ).

Similarly in ISSR markers, Keshar population showed the highest percentage of polymorphism, the highest numbers of effective alleles, Shannon index, and Nei's genetic diversity (Table 3). The lowest values of percentage polymorphism, number of effective alleles, Shannon index, and genetic diversity were obtained for the Tudar population. The highest genetic diversities within $\left(\mathrm{H}_{\mathrm{pop}} / \mathrm{H}_{\mathrm{sp}}\right)$ and among $\left(\mathrm{H}_{\mathrm{sp}}-\mathrm{H}_{\mathrm{pop}} / \mathrm{H}_{\mathrm{sp}}\right)$ populations for ISSR data were also observed in Keshar and Tudar populations, respectively.

Some specific RAPD bands were observed in the populations; for example, the OPA04-750, OPA13-650 and OPA02-350 bands were specific for Tudar, Bondon and Keshar populations, respectively, while no specific bands were observed in ISSR analysis. On the other hand, some RAPD bands, i.e., OPA13-550, OPA13-1300, OPA10-2000 and OPI12-450 were observed in all populations, except the Tudar population. Nei's genetic distance determined between pairs of wild olive populations for RAPD and ISSR data (Table 4) revealed that Tudar and Bokhoon populations had the greatest genetic distances at both molecular markers, while Keshar and Bokhoon populations had the shortest genetic distances.

Analysis of molecular variance (AMOVA) carried out for RAPD and ISSR data (Ta- 
ble 5) showed significant differences $(\mathrm{P}<0.01)$ among and between the populations studied for both molecular markers. The amount of genetic variation among the four populations was about $20 \%\left(F_{\mathrm{ST}}=0.205\right)$ in RAPD and $11 \%\left(F_{\mathrm{ST}}=0.114\right)$ in ISSR data. The $F_{\mathrm{ST}}$ pairwise analysis supported the significant difference in both molecular markers, among most of the populations studied (Table 6). Tudar and Bondon populations were significantly different, except for comparisons with ISSR markers $(\mathrm{P}=0.213)$.

Table 4. Nei's genetic distance between pairs of wild olive populations.
\begin{tabular}{lcccc} 
& Keshar & Bokhoon & Bondon & Tudar \\
\hline Keshar & - & 0.0565 & 0.1082 & 0.1979 \\
Bokhoon & 0.0954 & - & 0.1011 & 0.2132 \\
Bondon & 0.1403 & - & 0.205 & 0.1202 \\
Tudar & 0.2118 & 0.2843 & 0.2055 & - \\
\hline
\end{tabular}

Upper diagonal based on RAPD data and lower diagonal based on ISSR data.

Table 5. Analysis of molecular variance based on RAPD and ISSR data $(* \mathrm{P}<0.001)$.

\begin{tabular}{llccccc}
\hline & Source of variation & $\begin{array}{c}\text { Degrees of } \\
\text { freedom }\end{array}$ & $\begin{array}{c}\text { Sum of } \\
\text { squares }\end{array}$ & $\begin{array}{c}\text { Mean of } \\
\text { squares }\end{array}$ & $\begin{array}{c}\text { Percentage of } \\
\text { variation }\end{array}$ & $\begin{array}{c}\text { Fixation indices } \\
\left(F_{\text {ST }}\right)\end{array}$ \\
\hline RAPD & Among species & 3 & 211.550 & 70.517 & $20 \%$ & 0.205 \\
& Within species & 26 & 659.583 & 25.369 & $80 \%$ & $100 \%$ \\
\multirow{4}{*}{ ISSR } & Total & 29 & 671.133 & & $11 \%$ & 0.114 \\
& Among species & 3 & 47.767 & 15.922 & $89 \%$ & $100 \%$ \\
& Within species & 26 & 218.867 & 8.418 & & \\
& Total & 29 & 266.633 & & & \\
\hline
\end{tabular}

Table 6. Pairwise $F_{\text {ST }}$ values among wild olive populations studied.

\begin{tabular}{lcccc}
\hline & Keshar & Bokhoon & Bondon & Tudar \\
\hline Keshar & - & $0.105^{*}$ & $0.190^{*}$ & $0.311^{*}$ \\
Bokhoon & $0.082^{*}$ & - & $0.212^{*}$ & $0.379^{*}$ \\
Bondon & $0.080^{*}$ & $0.125^{*}$ & - & $0.211^{*}$ \\
Tudar & $0.184^{*}$ & $0.214^{*}$ & $0.071^{\mathrm{ns}}$ & - \\
\hline
\end{tabular}

Upper diagonal based on RAPD data and lower diagonal based on ISSR data. * Significant at $0.05(\mathrm{P}<0.05)$; ns $=$ nonsignificant. P values were estimated using 10,000 permutations.

\section{Genetic relationships among populations}

The NJ and UPGMA trees obtained from RAPD markers produced similar results, separating the wild olive populations. UPGMA tree based on Nei's genetic distance divided wild olive populations into four groups (Figure 1A). Keshar and Bokhoon populations showed more genetic affinity and were placed close to each other, while the Bondon population is more distant. The Tudar population was the most distant.

Similarly the UPGMA tree of ISSR data grouped the wild olive populations into four clusters (Figure 1B). The Keshar population showed more genetic affinity with the Bokhoon population. The Mantel test performed between RAPD and ISSR trees showed significant correlation between the two data set $(\mathrm{r}=0.99 ; \mathrm{t}=8.935 ; \mathrm{P}=1.000)$, indicating that these two types of molecular markers grouped the populations in a similar manner.

The PCO ordination plot of RAPD data (Figure 2) showed that the Keshar olive tree 
population grouped close to the Bokhoon tree population (Keshar trees Nos. 8, 9 and 10 are placed close to Bokhoon trees Nos. 18, 19, 20, and 21). The olive trees studied from Bondon and Tudar populations were grouped together and separated from the other populations. Some trees, such as Keshar No. 4 and Bondon No. 23 did not group with trees of their own population, due to genetic differences.

A

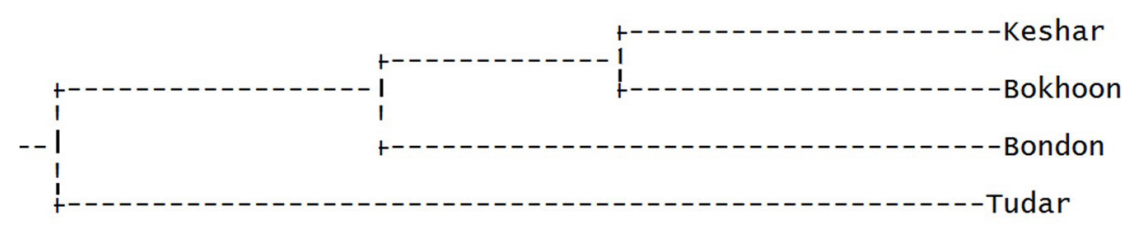

B

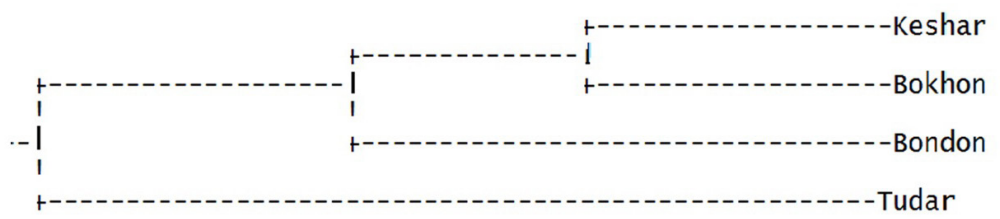

Figure 1. UPGMA dendrogram of four wild olive populations based on RAPD (A) and ISSR (B) data.

Factorial analysis: Axes $1 / 2$

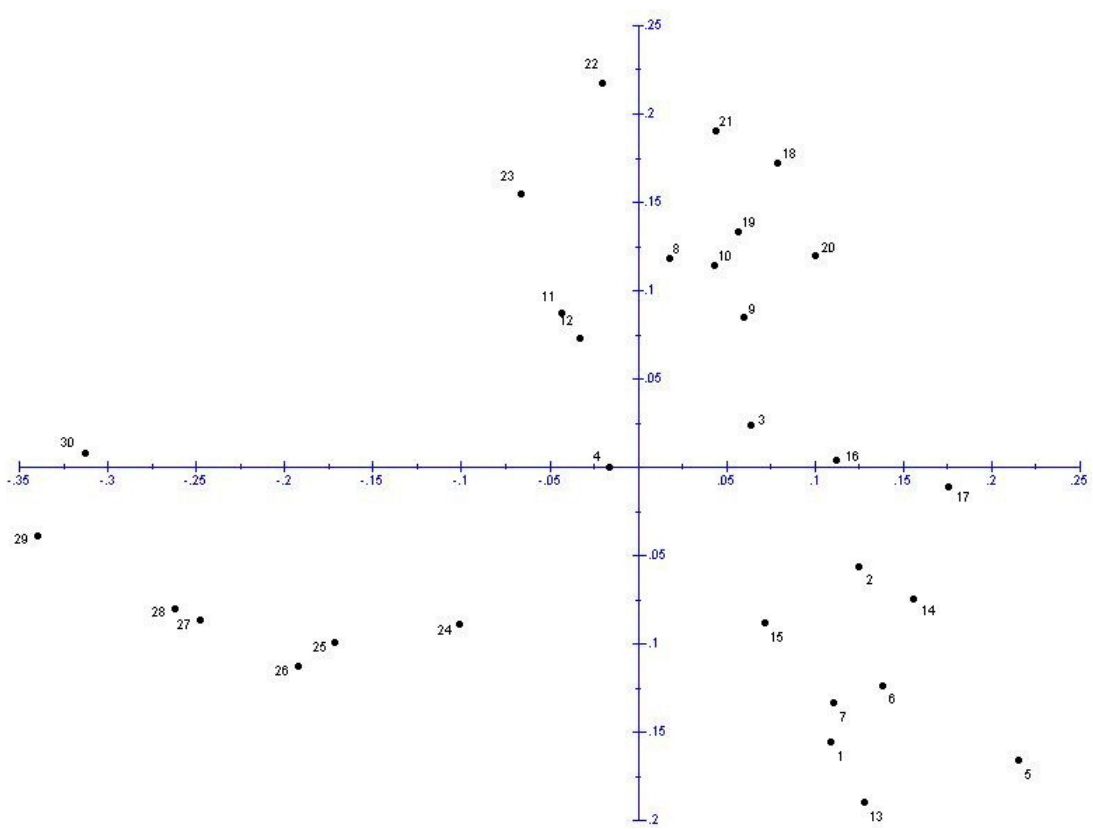

Figure 2. PCO ordination based on RAPD data. 1-12 = Keshar; $13-22=$ Bokhoon; $23-27=$ Bondon; 28-30 = Tudar trees. 
PCO analysis based on ISSR data could almost separate Tudar trees from the other trees (Figure 3). Keshar trees Nos. 1, 2, 3, 8, 9, 10, and 12 were placed separately, while the other Keshar trees (Nos. 4, 5, 6, 7, and 11) were grouped with Bokhoon trees. Some Bondon trees (Nos. 23, 24 and 25) showed more affinity to Keshar and Bokhoon trees.

Factorial analysis: Axes $1 / 2$

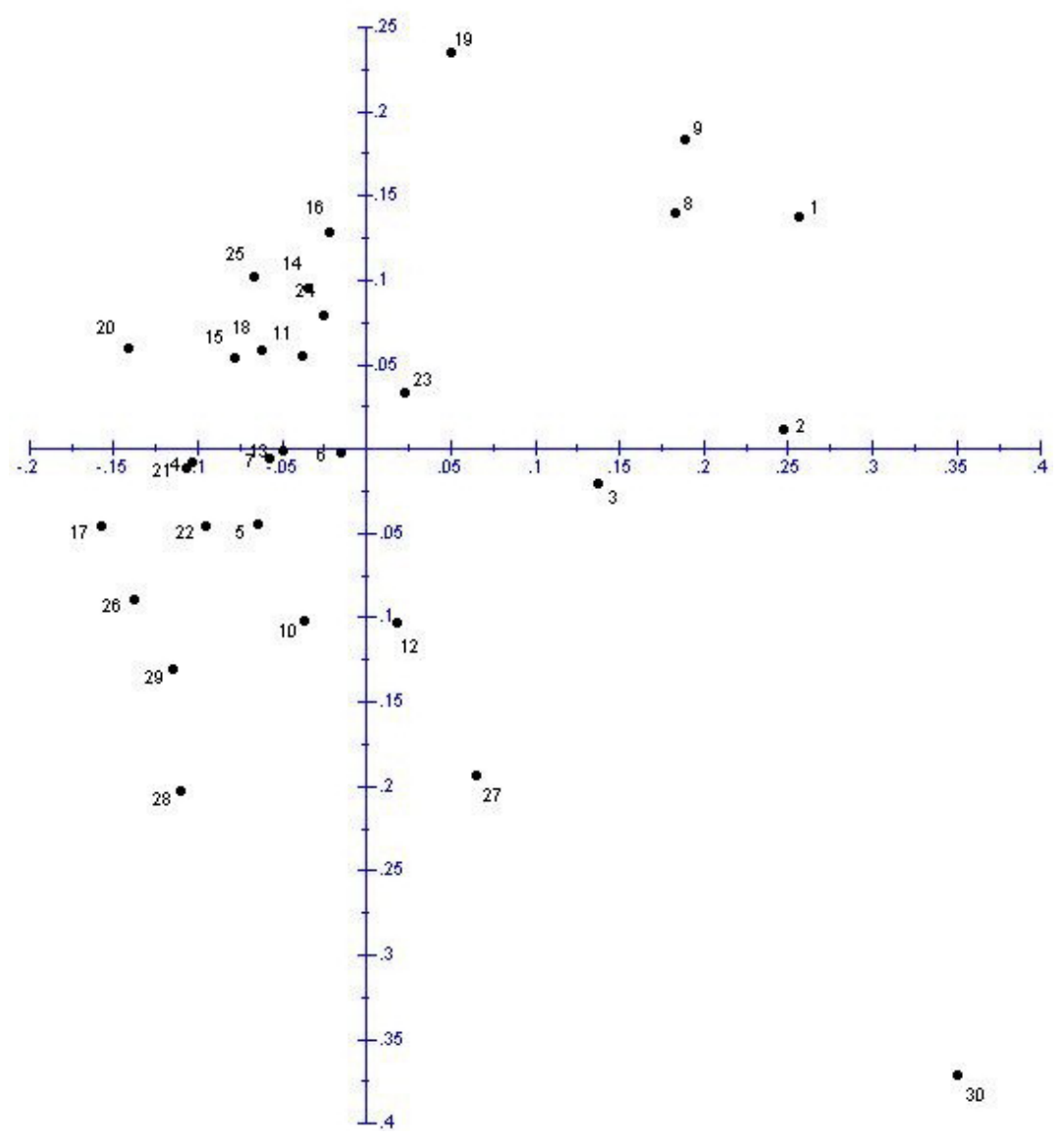

Figure 3. PCO ordination based on ISSR data. 1-12 = Keshar; 13-22 = Bokhoon; $23-27=$ Bondon; 28-30 = Tudar trees.

\section{DISCUSSION}

We found high allelic variation with 18 RAPD markers. Among them, seven RAPD primers gave the highest values of allele polymorphism $(100 \%)$, which will be valuable for wild olive population discrimination. The finding of high genetic diversity in Iranian wild olive populations is consistent with what has been reported from other studies using morphological and molecular (RAPDs, AFLPs and SSRs) markers (Angiolillo et al., 1999; Baldoni et al., 2006; Belaj et al., 2007; Sheidai et al., 2010). Here we report the usefulness of combined RAPD primers in demonstrating genetic diversity of wild olive popula- 
tions. However, we obtained this result with only one combined primer (OPC11/OPI18); more RAPD primer combinations need to be made and tested to evaluate these novel loci for producing informative bands with material from wild olive trees.

The high level of polymorphism at ISSR loci also indicates high genetic variability in wild olive trees, which is in agreement with other studies made on cultivated (Gemas et al., 2004; Terzopoulos et al., 2005; Essadki et al., 2006; Gomes et al., 2009; Martins-Lopes et al., 2009) and wild olive trees (Hess et al., 2000).

Both RAPD and ISSR data analyses showed intra- and inter-population genetic diversity in wild olive trees of Iran. The Keshar population was found to have the highest amount of within-population genetic diversity, while the highest genetic diversity compared to other populations was observed for the Tudar population. This latter result may be partly due to the limited number of trees collected from the Tudar population (only three trees were available). The $F_{\text {ST }}$ pair wise analysis of molecular data performed between populations showed significant genetic differences among olive populations for both RAPD and SSR molecular markers. Such high genetic divergence may be due to the occurrence of different mutations including insertions/deletions in each population and a lack of genetic exchange between populations.

AMOVA results also revealed a higher level of intra-population genetic variation (more than $80 \%$ ) compared to that among populations. This is in agreement with the results obtained from most woody perennial outbreeding species, with most variation being within populations (Hamrick and Godt, 1989; Hamrick et al., 1992), and is similar to what was found in other studies made on wild (Baldoni et al., 2006; Rubio de Casa et al., 2006; Belaj et al., 2007) and cultivated olives (Belaj et al., 2004; Gemas et al., 2004). Consequently, we may consider each wild olive population studied as a separate gene pool in Iran. However, similarity observed between some of the olive trees belonging to different populations (based on cluster and PCO analyses) shows some gene flow between these populations. Olive pollen carried by birds (Spennemann and Allen, 2000) could be a reason for gene dispersal as far as $200 \mathrm{~km}$, although geographical barriers limit inter-population pollen dispersal. Sheidai et al. (2010) also found intra-specific variation in O. europaea ssp cuspidata in Iran.

The ISSR molecular markers did not discriminate the wild olive trees as clearly as did RAPD markers, although ISSR markers did reveal a high level of genetic variation within and among populations. This could be due to differences in the DNA nucleotides amplified by these two molecular markers and also due to different mutations occurring in them. Therefore, for delimitation of wild olive populations and to achieve a better understanding of genetic diversity within populations, it is better to use both molecular markers and their possible combinations.

In conclusion, we found a high degree of genetic diversity among $O$. europaea ssp cuspidata populations located in southern Iran and that RAPD and ISSR markers are useful molecular tools to discriminate populations and evaluate genetic variation in wild olives.

\section{ACKNOWLEDGMENTS}

The authors gratefully acknowledge the Science and Research Branch of Islamic Azad University (SRBIAU).

\section{REFERENCES}

Angiolillo A, Mencuccini M and Baldoni L (1999). Olive genetic diversity assessed using amplified fragment length polymorphisms. Theor. Appl. Genet. 98: 411-421. 
Azadi R (2005). Family Oleaceae. Flora of Iran. Res. Inst. Forest Range Lands 48: 36.

Baldoni L, Tosti N, Ricciolini C, Belaj A, et al. (2006). Genetic structure of wild and cultivated olives in the central Mediterranean basin. Ann. Bot. 98: 935-942.

Belaj A, Cipriani G, Testolin R, Rallo L, et al. (2004). Characterization and identification of the main Spanish and Italian olive cultivars by simple-sequence-repeat markers. Hortscience 39: 1557-1561.

Belaj A, Munoz-Diez C, Baldoni L, Porceddu A, et al. (2007). Genetic diversity and population structure of wild olives from the North-Western Mediterranean assessed by SSR markers. Ann. Bot. 100: 449-458.

Besnard G, Baradat Ph, Chevalier D, Tagmount A, et al. (2001). Genetic differentiation in the olive complex (Olea europaea) revealed by RAPDs and RFLPs in the rRNA genes. Genet. Resour. Crop Evol. 48: 165-182.

Besnard G, Garcia-Verdugo C, De Casas RR, Treier UA, et al. (2008). Polyploidy in the olive complex (Olea europaea): evidence from flow cytometry and nuclear microsatellite analyses. Ann. Bot. 101: 25-30.

Essadki M, Ouazzani N, Lumaret R and Moumni M (2006). ISSR variation in olive-tree cultivars from Morocco and other western countries of the Mediterranean Basin. Genet. Resour. Crop Evol. 53: 475-482.

Gemas VJV, Almadanim MC, Tenreiro R, Martins A, et al. (2004). Genetic diversity in the olive tree (Olea europaea L. subsp. europaea) cultivated in Portugal revealed by RAPD and ISSR markers. Genet. Resour. Evol. 51: 501-511.

Gomes S, Martins-Lopes P, Lopes J and Guedes-Pinto H (2009). Assessing genetic diversity in Olea europaea L. using ISSR and SSR markers. Plant Mol. Biol. Rep. 27: 365-373.

Green PS (2002). A revision of Olea L. (Oleaceae). Kew Bull. 57: 91-140.

Hamrick JL and Godt MJW (1989). Allozyme Diversity in Plant Species. In: Plant Population Genetics, Breeding and Genetic Resources (Brown AHD, Clegg MT, Kahler AL and Weir BS, eds.). Sinauer Associates, Sunderland, 43-63.

Hamrick JL, Godt MJW and Sherman-Broyles SL (1992). Factors influencing levels of genetic diversity in woody plant species. New Forests 6: 95-124.

Hess J, Kadereit JW and Vargas P (2000). The colonization history of Olea europaea L. in Macaronesia based on internal transcribed spacer 1 (ITS-1) sequences, randomly amplified polymorphic DNAs (RAPD), and intersimple sequence repeats (ISSR). Mol. Ecol. 9: 857-868.

Mantel N (1967). The detection of disease clustering and a generalized regression approach. Cancer Res. 27: 209-220.

Martins-Lopes P, Gomes S, Lima-Brito J, Lopes J, et al. (2009). Assessment of clonal genetic variability in Olea europaea L. "Cobrançosa" by molecular markers. Sci. Hort. 123: 82-89.

Nei M (1973). Analysis of gene diversity in subdivided populations. Proc. Natl. Acad. Sci. U. S. A. 70: 3321-3323.

Noormohammadi Z, Hosseini-Mazinani M, Trujillo I, Rallo L, et al. (2007). Identification and classification of main Iranian olive cultivars using microsatellite markers. Hortscience 42: 1545-1550.

Omrani-Sabbaghi A, Shahriari M, Falahati-Anbaran M, Mohammadi AS, et al. (2007). Microsatellite markers based assessment of genetic diversity in Iranian olives (Olea europaea L.) collections. Sci. Hort. 112: 439-447.

Peakall R and Smouse PE (2006). GENALEX 6: genetic analysis in Excel. Population genetic software for teaching and research. Mol. Ecol. Notes 6: 288-295.

Podani J (2000). Introduction to the Exploration of Multivariate Data. Backhuyes Publishers, Leide.

Rohlf FJ (1998). NTSYS-pc. Numerical taxonomy and multivariate analysis system. Version 2.00. Exeter Software, Setauket.

Rubio de Casa R, Besnard G, Schonswetter P, Balaguer L, et al. (2006). Extensive gene flow blurs phylogeographic but not phylogenetic signal in Olea europaea L. Theor. Appl. Genet. 113: 575-583.

Sheidai M, Noormohammadi Z, Dehghani AR, Parvini F, et al. (2010). Intra-specific morphological and molecular diversity in brown olive (Olea cuspidata) of Iran. Sci. Asia 36: 187-193.

Spennemann DHR and Allen LR (2000). The Avian dispersal of olives Olea europaea: implications for Australia. EMU 100: 264-273.

Terzopoulos PJ, Kolano B, Bebeli PJ, Kaltsikes PJ, et al. (2005). Identification of Olea europaea L. cultivars using intersimple sequence repeat markers. Sci. Hort. 105: 45-51.

Yeh FC, Yang RC and Boyle T (1999). Population Genetic analysis (POPGENE 1.31). A joint project of University of Alberta and Center for International Forestry Research, Edmonton. 